\title{
AN ASSESSMENT OF INDONESIAN CHARTER AIRLINE WEBSITE QUALITY
}

\author{
Ajeng Fadillah Idhar ${ }^{1}$, Anky Maolana $\mathbf{P}^{2}$, Basri Fahriza ${ }^{3}$ \\ 1. STMT Trisakti, 2. STMT Trisakti, 3. STMT Trisakti \\ $\square$ corresponding author: Maulanaanky@gmail.com
}

\begin{abstract}
The usage of website is increasingly important for business in general including aviation industry because it provides additional benefits for the business. That is the reason why managing and maintaining a good website is very important in this digital age. One method to measure website quality was using the nine composite criteria of website assessment. The purpose of this study is to improve Premiair website quality, as one of the players in the air charter business in Indonesia. Using the nine composite criteria as an assessing framework and for improvement purpose, we benchmark Premiair website with XOJET website. Based on the interview, the result shows that there are indeed rooms for Premiair website to improve its quality. The researchers suggest major changes to its website in order to create a better quality website.
\end{abstract}

Keywords: Website quality, Assessment, Nine Composite Criteria, Air Charter, Premiair

\section{Introduction}

Technology is now used in almost every part of human lives from social, politic and economic (Purwanto, Tinggi, Tristakti, Rafi, \& Pongoh, 2016) and it gives many advancement especially in business sector (Simarmata, Keke, \& Panjaitan, 2016) one technology often used in business is website. The usage of website is not a new thing in the aviation industry. Many airlines have developed their website in spite of its business type whether it is a business to business (B2B) or business to costumer (B2C) type, and it is proven to increase their business efficiency, effectiveness and competitive advantage (Hanke \& Teo, 2003). The previous research also proved that there was a relation between website quality and business performance, the research found websites that have a good quality influence air travelers to purchase tickets (Fahzi, Sam, \& Tahir, 2009).

Premiair as a charter airline uses website to reach their costumers and gives costumers information related to their product and service in air charter business. One of the things we notice when we are going through their 
webpage is that there are rooms for improvements from its website design and the information given seems lack of information, compared to XO JET.

Air charter service provider website and any business in general should be maintained and well managed as it is one of the gateway for potential customer to reach them (Ryan \& Jones, 2009). The content of website quality has directly affected the customers' view of the product quality, this includes how the company gives information about the products on websites (Wells, Valacich, \& Hess, 2011). Website quality is also related to the costumer purchasing intentions (Fahzi et al., 2009). Maintaining and managing website content are very important for business process as they relate to customers' purchasing intention to generate revenue.

This research focuses on analyzing the website quality of Premiair as sample subject for executive JET provider in Indonesia, benchmarking Premiair's website with XOJET, and comparing both websites from the 9 composite criteria. The purpose of this research is to assess Premiair website content using the website quality assessment framework and to compare XOJET and Premiair website for benchmarking purposes.

\section{Method}

This research used a qualitative comparative research. The assessment framework used a combination of several web quality assessment criteria done by the previous researchers. The previous research used as main references and guideline for this research was conducted by Moustakis et al. which assessed website through nine composite criteria (Moustakis, Litos, Dalivigas, \& Tsironis, 2004) and the nine composite criteria were further developed using various research as secondary references and with intention to create better instrument. This research provides additional insight on website quality assessment criteria. Figure 1 display the 9 composite criteria for website quality assessment. 


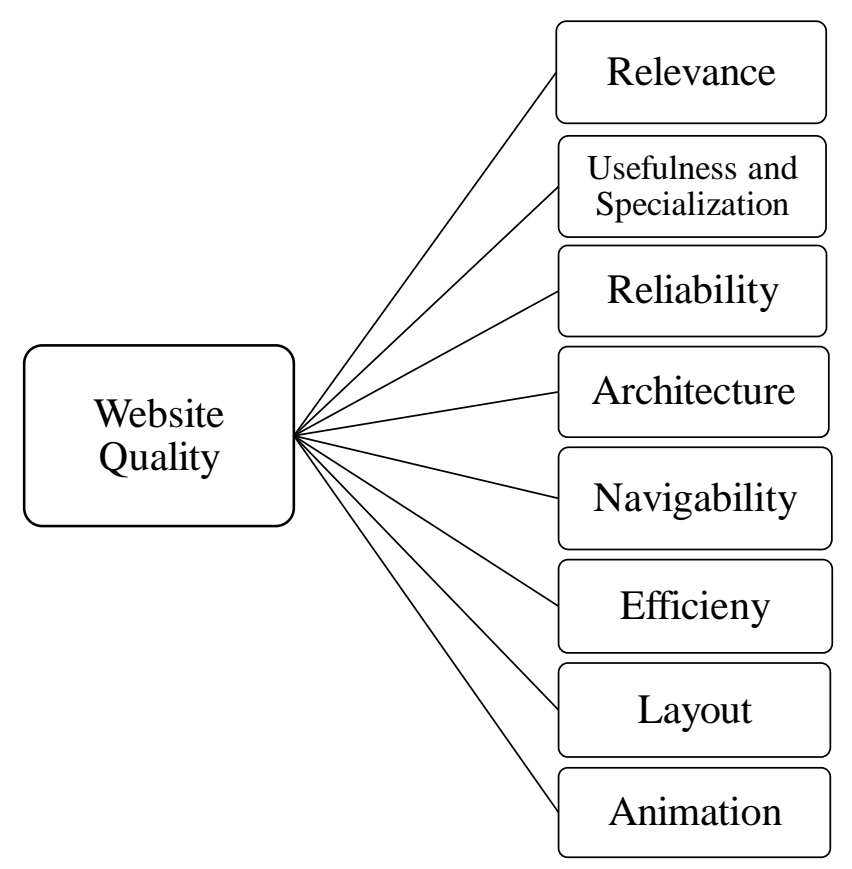

Figure 1. The 9 composite criteria for assessing website quality (Moustakis et al., 2004)

The sampling method used stratified purposive sampling methods (Willis, 2007). The sample was non-consumer of the air charter but shared one similar characteristic. We determined their educational backgrounds. The population sample was divided into 2 groups of people who achieved higher education (undergraduate student or higher) are majoring in IT and Aviation management. This sample background was considered appropriate because this research focuses on assessing the web quality without investigating its effect to Premiair Business that's why non costumer of air charter is appropriate. The assessment criteria could be classified into two main categories, first Information quality which include relevance, usefulness, reliability, specialization (Moustakis et al., 2004). It can optimally be assessed by sample from aviation management educational background. And the second, the IT major education background will optimally assess web specifications criteria, consist of architecture, layout, efficiency, navigability and animation (Moustakis et al., 2004) although both group of respondent were asked about all 9 criteria assessment question.

We interviewed 19 respondents. This number of sample was considered sufficient enough as the previous research proved 12 respondents would be 
enough to achieve data saturation (Guest, Bunce, \& Johnson, 2006) (Crouch $\&$ McKenzie, 2006). Meanwhile, the researchers believe data saturation for this research had been reached after the $13^{\text {th }}$ interview conducted with the respondent.

This research used primary data taken from respondents, the primary data were obtained by doing general interview with guide approach to the respondents (Turner, 2010) (Willis, 2007). The interview was done by asking two set of questions to the respondents while exploring both Premiair and XOJET websites. The first set of questions consisted of the respondent personal identity and data and the second set of questions was formulated from the nine composite web assessment criteria as main guidelines to both assess Premiair websites quality. Then, compare it to XOJET as a benchmark website. Other questions related to the main questions were asked if necessary for exploration purpose The last step is to analyze which website performs better based on the interview questions. The study used both Premiair and XOJET Websites for comparison subject. The secondary research data used literature review of previous journals, articles, and books related to website quality assessment as guidance and references in doing the research.

The researchers analyzed the obtained data by comparing the respondent interview result to each website, reviewing their response to the question asked, highlighting important points in the interview and summarizing from what aspect Premiair website should be improved. The researchers use the XOJET result as a benchmark for Premiair improvement.

\section{Discussion and Result}

The website quality assessment criteria developed by Moustakis et al, was derived from larger group of criteria and sub-criteria taken from the International Academy of Digital Arts and Sciences and in Webby Awards for assessing websites quality and various literatures. Statistical factor analysis supports the reduction of those criteria into nine composite criteria for Website quality scoring framework (Moustakis et al., 2004). 
Each criteria holds different value corresponded to their contribution to the website quality with the criteria of relevance which has the highest contribution value and animation offers least value. We develop these nine composite criteria into a set of questions to assess Premiair and XOJET website by personalizing and customizing the questions into air charter business model.

\section{Relevance}

Researchers found that XOJET website generally provides better information, although information about what service provided, fleet, and seat capacity are already presented by both website. One of XOJET features called Book a trip (quick link) helps the customers to find available routes and book the flight directly. XOJET provides the ease of communication with clearly defined "contact" menu and several social media for other means of communication. In Premiair however, there is no quick link to help customers in arranging their flights, there is also no information about available routes, and the "contact" menu is hard to find with the current placement and color selection.

The relevance criteria assessed the website of its website content, whether the information provided and its content have the relevance or not to meet general customers' inquiry (Moustakis et al., 2004). It is related to information of quality component such as its product and service information (Liu \& Arnett, 2000). Based on our observation, air charter of general inquiries may include what services are provided, aircraft fleet, contact, available routes, ordering process, seat capacity and contact. We asked our respondent whether the information given in the website about the general inquiries in air charter adequate enough and how is their opinion on the contact provided on the website. Interview result shows that XOJET is better in providing this information, which proves that XOJET website has better relevance to customer inquiries of products and service information than Premiair's,

It is recommended that Premiair add information about their routes, ordering process or add similar feature like XOJET Book a Trip. The 
researchers suggest the "contact" menu to be moved to the top of the website and make it as one of the menu aligned with "our member" menu etc to create easy communication. It is due to contact usually is the basic inquiry to look for by web visitors.

\section{Usefulness and Specialization}

Usefulness is a subjective criteria, measuring web quality based on whether the website could provide specific visitor inquiries and it's highly related to specialization because specialization itself is the criteria to measure website quality based on how detailed information is provided by the website (Moustakis et al., 2004). So if more detailed information provided, more specific inquiries could be fulfilled by the website. It is related to WebQual ${ }^{\mathrm{TM}}$ aspect of information called "fits to task" and "tailored communications" (Kim \& Stoel, 2004). We asked our respondents their opinion on the detail information provided by each website. The respondents agree that XOJET provides better usefulness and certainly is better in term of specialization.

XOJET provides information such as fleet description and aircraft interior information with $360^{\circ}$ view and tour feature, flying range, technical specification, and price range, and again its Book A trip features. XOJET level of detailed information agreed to be better if it is compared to Premiair among the research respondents. Based on the respondents' interview, it is clear that XOJET detailed information on its web is better than premiair. Premiair is behind in giving detail information in many of their Fleets which indicates inconsistency. Many of their fleet page do not give any information about cabin interior and technical specification. Some fleet information even do not give basic description. There comes up a conclusion that the visitor will surely find XOJET website to be more useful and detailed than Premiair when looking for information.

Based on the findings, Premiair should update their information and provide better detail information in its website, such as adopting the $360^{\circ}$ view of the cabin interior which is preferable as it gives more complete information to the web visitor. Even though, pictures of cabin interior in each fleet are sufficient enough to inform website visitor. A consistent detailed information 
on each fleet information also needs to be done in order to increase website usefulness and specialization.

Reliability

The result shows XOJET represents better reliability of information rather than Premiair. This is heavily related to the information detail as XOJET provides higher degree of information detail said most of this respondent. The reliability criteria discusses about information accuracy and one method to measure accuracy could be seen when the information uploaded is done (Moustakis et al., 2004) for this criteria we ask questions about whether the information provided in the website is accurate or depict accuracy from the respondent point of view and whether they notice if there is any time info of when does the paper uploaded.

Most respondents think in a business of service provider especially air charter, time information is important enough to convey a sense of accuracy of air charter product. Most of the respondents also agree the detail information provided by XOJET gives better sense of accuracy of product information. Some of the respondents which include one experienced worker in the air transportation industry suggested in order to give better accuracy of information provided, the website should include reviews or testimony of the previous customers. The researchers recommend Premiair website to provide higher detail of information and to establish a review column from previous customers to create higher web reliability for website visitor.

Architecture

From architecture assessment point, XOJET has better management of the architecture, with most of our respondents agreed its website is more users friendly and has better user experience (UX). This includes placement of XOJET menus, buttons, picture and text, making respondents enjoy their experience while using XOJET web. XOJET website also has a good selection of color representing the luxurious image of air charter, it uses black and white color making XOJET user interface (UI) preferable than Premiair. The respondents described it to be more clean, elegant, professional and exclusive. In order to have a good quality website, good management of web 
content, information, animations, effect, buttons placement and usage of color is required (Moustakis et al., 2004). The criteria questions for this paper can be expanded further by looking into aspect of the web appearance on Aldwani and Palvia research (Aladwani \& Palvia, 2002)

As explained before, the interview result shows positive response for XOJET website architecture, for Premiair website, the selection of color of several background, text size and menu location for the several menus considered to be a mistake. As an example, Premiair web contact and fleet menu make some mistakes which also happen in their fleet overview, floorplan, technical specification, and picture gallery. Because of this mistake, the menu is either indistinguishable with the background or difficult to see or spot by the respondents. Although for overall website theme color selection with gold and maroon on it website, premiair also represents the image of luxury.

In order to get this result, we asked our respondent whether the website shown good management of its menu, button, picture, descriptions etc or not and also how is the color theme used in the website represent the exclusive image of air charter industry. Based on this result, it is clear Premiair website architecture still behind on its quality, Premiair website need to create better web architecture and UX. This is necessary in order to have better quality website and our findings indicates Premiair web architecture affects other website assessment criteria such as its navigability and layout criteria. The web architecture related to the placement of the certain menu, text size and color selection needs to be revised.

Navigability

Navigability scores of the web quality based on how easy and effortless it is to navigate, move around the website from the visitor perspective (Moustakis et al., 2004) The easier it is for visitor to move around the site, the better its navigability is and vice versa. It is related to technical adequacy in Aladwani et al paper. The research mentioned that the availability of search facilities is one of the measurement of a website quality (Aladwani \& Palvia, 2002). We asked our respondents to assess the website navigation help, and 
how the whole navigation experience while experiencing the website. From the interview, we discovered both website provide navigation helps with XOJET providing search engines for routes and trip planning (product) meanwhile Premiair only Sitemaps as means of navigation to go around the web.

In terms of overall experience, XOJET proves to be easier to navigate around which is related to the UI and UX of the website. As previously said, XOJET has better UI and UX. These help the visitors to develop positive experience navigating around the website. This is the opposite of Premiair website UX, as explained before, the lack of quality UX generates less positive navigation experience for the website visitor. The clear result shows there is connection between website navigation and its architecture. In order to improve navigability of Premiair website, Premiair should update its architecture.

\section{Efficiency}

Efficiency measures the technical performance of the web itself, such as how fast or slow the website loads meaning the faster the website loads the better the efficiency is. Website should mention how long the loading will take (either in bytes or time) (Moustakis et al., 2004). Kim and Stoel research website response of time instrument can be adopted (Kim \& Stoel, 2004) to measure website efficiency. The question to assess this criteria include the questions of whether the website took a long time to loads and whether the website give information of how long will the website loads or not. The researchers discover both websites are efficient. Most of the time both websites took a short period of time to load but during several interview both website took longer to load. Short or long time is actually relative to the availability of the internet connection speed. That is why measuring efficiency is difficult with changing internet connection speed during several interviews. Both websites, however, do not mention how long a page will load in most pages. XOJET only provides how long the page will load in their $360^{\circ}$ feature. The rest of their webpage is not available, meanwhile Premiair only mentions the copyright year of the webpage. 
Judging from these two points of view, both websites perform equally well, although the researchers suggest the loading time information should be provided because providing such feature will add the website efficiency. Layout

The respondents were asked is the website is unique compare to other websites, and most of our respondents agreed XOJET website is more unique in its layout compare to Premiair. It is because XOJET website performs better in architecture criteria. The respondents response seem to be influenced by XOJET selection of theme color, UI and EX (its architecture). This finding is in line with the theory which said layout is connected with architecture (Moustakis et al., 2004). Meanwhile interview result with our respondents indicates Premiair website looks very general and no uniqueness.. This is strongly linked to Premiair architecture. The researchers suggest in order to have better layout Premiair should improve its architecture.

Animation

A scoring criteria measuring a web moving aspect in its presentations of information and its website user interaction is more recognizable for animation used better on the website (Moustakis et al., 2004). We asked our respondents about their opinion on the animation used in the website, whether it is attractive and interesting or not. The criteria of both websites which have used sufficient animation on Premiair website animation on their website is easy to recognize by the respondent as it is located in the home of Premiair website, meanwhile XOJET animation feature of $360^{\circ}$ view is better but apparently in order to experience the feature, the user needs additional software. The researchers conclude adequate animation is already used by Premiair and further improvement is preferable. The usage of $360^{\circ}$ view for XOJET cabin tour is one of possible improvement for animation criteria for Premiair website.

\section{Conclusion}

This research aims to improve Premiair website quality for the same purposes by benchmarking Premiair with XOJET using the same assessment 
framework. Our findings confirm Premiair website is lack of the quality that a business website should have. The research result describes in a clear explanation of what Premiair need to improve on the website. The researchers conclude that Premiair should focus on the improvement of their website in the criteria of relevance, usefulness, specialization, reliability, especially from its architecture and specialization quality which proves to affect the other criteria of website quality. The researchers put detailed and practical suggestion on how to improve Premiair website based on the criteria as explained in the discussion. However, this research focuses on assessing website quality, without studying and analyzing the impact of the website quality to their business conduct. We suggest future research to analyze the effect of website quality to air charter marketing efficiency. This is due to website playing a major role in connecting potential customers to company and it easier to gain information through website.

\section{References}

Aladwani, A. M., \& Palvia, P. C. (2002). Developing and validating an instrument for measuring user-perceived web quality. Information and Management, 39(6), 467-476. https://doi.org/10.1016/S03787206(01)00113-6

Crouch, M., \& McKenzie, H. (2006). The logic of small samples in interviewbased qualitative research. Social Science Information, 45(4), 483-499. https://doi.org/10.1177/0539018406069584

Fahzi, M., Sam, M., \& Tahir, M. N. H. (2009). Website Quality and Costumer Online Purchase Intention of Air Ticket. International Journal of Engineering \& Science.

Guest, G., Bunce, A., \& Johnson, L. (2006). How Many Interviews Are Enough? Field Methods, 18(1), 59-82. https://doi.org/10.1177/1525822X05279903

Hanke, M., \& Teo, T. S. H. (2003). Meeting the Challenges in Globalizing Electronic Commerce at United Airlines. Journal of Information Technology Case and Application Research, 5(4), 21-38. https://doi.org/10.1080/15228053.2003.10856031

Kim, S., \& Stoel, L. (2004). Dimensional hierarchy of retail website quality. Information and Management, 41(5), 619-633. https://doi.org/10.1016/j.im.2003.07.002

Liu, C., \& Arnett, K. P. (2000). Exploring the factors associated with Web site success in the context of electronic commerce. Information \& Management, 38(1), 23-33. https://doi.org/10.1016/S03787206(00)00049-5 
Moustakis, V. S., Litos, C., Dalivigas, A., \& Tsironis, L. (2004). Website Quality Assessment Criteria. Proceedings of the Ninth International Conference on Information Quality (ICIQ-04), 59-73.

Purwanto, B., Tinggi, S., Tristakti, M. T., Rafi, S., \& Pongoh, H. (2016). Human Resources on Transport, Telecommunication, and Tourism Sectors in Global Perspective, 3(3), 327-338.

Ryan, D., \& Jones, C. (2009). Summary for Policymakers. Digital Marketing: Marketing strategies for engaging the digital generation. https://doi.org/10.1017/CBO9781107415324.004

Simarmata, J., Keke, Y., \& Panjaitan, F. (2016). the Airline Customer' S Buying Decision Through Online Travel Agent : a Case Study of the Passengers, $I V(3)$, 335-349.

Turner, D. W. (2010). Qualitative interview design: A practical guide for novice investigators. The Qualitative Report, 15(3), 754-760. https://doi.org/http://www.nova.edu/ssss/QR/QR15-3/qid.pdf

Wells, J., Valacich, J., \& Hess, T. (2011). What Signals Are You Sending? How Website Quality Influences Perceptions of Product Quality and Purchase Intentions. MIS Quarterly, 35(2), 373-396. https://doi.org/Article

Willis, J. (2007). Foundations of Qualitative Research: Interpretive and Critical Approaches. Qualitative Research, 356. https://doi.org/10.4135/9781452230108 